\title{
Sensitivity Analysis of Geometrical Parameters on a Double-Sided Linear Switched Reluctance Motor
}

\author{
J. G. Amoros, Member, IEEE, and P. Andrada, Member, IEEE
}

\begin{abstract}
This paper presents a detailed sensitivity analysis of the effect of several geometrical parameters on the performance of a double-sided linear switched reluctance motor (LSRM). The analysis was conducted in two dimensions using finite-element method and takes into account only one part of the LSRM. This paper first investigates the powerful influence of stator- and translator-pole widths on force profiles. It then shows how these performance parameters are influenced by stator-pole length, translator-pole length, stack length, yoke length, and air gap. Experimental results confirm that the 2-D finite-element sensitivity analysis proposed in this paper may prove to be a useful tool for optimizing the geometry of a double-sided LSRM.
\end{abstract}

Index Terms-Analytical force calculations, end effects, finite-element analysis, linear switched reluctance machines, machine design, sensitivity analysis.

\section{NOMENCLATURE}

$b_{p} \quad$ Stator-pole width (in meters).

$c_{p} \quad$ Stator-slot width (in meters).

$T_{p} \quad$ Stator-pole pitch (in meters).

$N_{p} \quad$ Number of active poles per side (stator).

$l_{p} \quad$ Stator-pole length (in meters).

$b_{s} \quad$ Translator-pole width (in meters).

$c_{s} \quad$ Translator-slot width (in meters).

$T_{s} \quad$ Translator-pole pitch (in meters).

$N_{s} \quad$ Number of passive poles per side (translator).

$l_{s} \quad$ Translator-pole length (in meters).

$h_{y} \quad$ Yoke height (in meters).

$L_{W} \quad$ Stack length (in meters).

$g \quad$ Air-gap length (in meters).

$P S \quad$ Stroke (in meters).

$S \quad$ Distance between aligned and unaligned positions (in meters).

$m \quad$ Number of phases.

$\alpha_{p} \quad$ Normalized stator-pole width.

$\beta_{p} \quad$ Normalized stator-pole length.

$\alpha_{s} \quad$ Normalized translator-pole width.

$\beta_{s} \quad$ Normalized translator-pole length.

Manuscript received December 23, 2008; revised September 2, 2009. First published September 22, 2009; current version published December 11, 2009. This work was supported in part by the Spanish Ministry of Education and Science and in part by the European Regional Development Fund under Grants DPI2006-09880 and DPI2007-66872 C02-02.

J. G. Amoros is with the Universitat Politecnica de Catalunya (UPC), 08034 Barcelona, Spain, and also with the Universitat Rovira i Virgili, 43007 Tarragona, Spain (e-mail: jordi.garcia-amoros@urv.cat).

P. Andrada is with the Engineering School of Vilanova i la Geltrú (EPSEVG), Department of Electrical Engineering, Universitat Politecnica de Catalunya (UPC), 08034 Barcelona, Spain.

Digital Object Identifier 10.1109/TIE.2009.2032208

\author{
$\delta_{y} \quad$ Normalized yoke length. \\ $\gamma_{w} \quad$ Normalized stack length. \\ $x \quad$ Translator position (in meters). \\ $N_{1} \quad$ Number of coils per pole. \\ $L_{\mathrm{au}} \quad$ Unsaturated aligned inductance (in henries). \\ $L_{u} \quad$ Unaligned inductance (in henries). \\ $L_{\text {as }} \quad$ Saturated aligned inductance (in henries). \\ $L_{\text {as }}^{\prime} \quad$ Saturated aligned incremental inductance (in henries). \\ $I_{B} \quad$ Flat-topped current peak (in amperes). \\ $J_{B} \quad$ Current density peak (in amperes per square meter). \\ $B_{p} \quad$ Magnetic flux density in the stator pole (in teslas). \\ $K_{s} \quad$ Slot fill factor. \\ $N_{\text {pp }} \quad$ Number of stator poles per phase. \\ $M \quad$ Number of modules series connected.
}

\section{INTRODUCTION}

$\mathbf{L}$ INEAR SWITCHED reluctance motors (LSRMs) are becoming attractive candidates for use as linear drives for several reasons: they only have concentrated windings on the stator or translator; they are ruggedly built; they have low expected manufacturing costs; and they have a good faulttolerance capability [1]. LSRMs can be classified as transverse or longitudinal flux. With transverse flux, the plane that contains the flux lines is perpendicular to the line of movement. Reference [2] presents a design procedure for transverse-flux LSRMs. In longitudinal flux, the plane that contains the flux lines is parallel to the line of movement. Reference [3] describes a design procedure for longitudinal-flux LSRMs. Other types of longitudinal-flux LSRMs are presented in [4], with coupled flux paths, and in [5] with uncoupled flux paths for a magnetic levitation system. Reference [6] analyzes a highforce longitudinal-flux double-sided double-translator LSRM. Recently, longitudinal-flux LSRMs have been proposed for applications such as precise motion control [7], [8] and as propulsion systems for railway vehicles [9] or vertical elevators [10]-[12].

The sensitivity of geometry in the performance of rotating SRMs has been extensively described in the literature [13][16]. The sensitivity of pole arcs on average torque is studied using an analytical method and 2-D finite-element analysis (2-D FEA) in [13]. In [14], the sensitivity analysis is conducted by means of an analytical model based on air-gap permeance and the equivalent magnetic circuit. Reference [15] studies the sensitivity of pole arcs and air-gap length on the average torque using 2-D FEA. In [16], the sensitivity of the stator and rotor pole arcs is studied to minimize torque ripple. 
Up to now, very little has been published on the sensitivity of geometrical parameters in LSRM performance. However, it is important to mention the work presented in [17] on the feasible stator- and translator-pole arrangements in longitudinal- and transverse-flux LSRMs. This paper intends to address this gap in the literature by studying how several geometrical parameters influence the inductance and force profile of an LSRM. The study focuses on longitudinal-flux LSRMs for high-forcedensity applications, and therefore, transverse-flux LSRMs are out of the scope of this paper. Although the sensitivity analysis has been created for a double-sided LSRM, because ideally it does not produce a net normal force on the translator, the study can be also applied to different kinds of LSRMs such as singlesided or modified high-force-density LSRMs [12].

This paper first presents an analytical approach to the average propulsion force determined using the nonlinear energy conversion loop, in which the unaligned magnetization curve is assumed to be a straight line and the aligned magnetization curve is represented by two straight lines [18], [20]. This first approach shows the influence of several geometrical parameters-stator-pole magnetic flux density, current density, and inductance relationships - on average force. In order to study the problem in greater depth, a 2-D FEA including end effects was conducted with the aim of completing former research which focused only on the influence of stator-pole width $\left(b_{p}\right)$ and translator-pole width $\left(b_{s}\right)$ [21]. Thus, this paper also includes a sensitivity analysis of stator-pole length $\left(l_{p}\right)$, translator-pole length $\left(l_{s}\right)$, stack length $\left(L_{W}\right)$, yoke length $\left(h_{y}\right)$, and air gap $(g)$ in order to determine how these affect linear motor performance.

The main contribution of this paper, apart from compensating for the absence of consistent sensitivity analyses in the literature, is to provide some guidelines for the design of longitudinal-flux LSRMs. As a result of this research, a prototype has been built for which experimental tests show a good correlation of force with the proposed 2-D finite-element sensitivity study.

This paper is organized as follows. Section II describes the LSRM and presents an analytical approach to average propulsion force. Section III gives the basis of the 2-D sensitivity analysis. Section IV presents the sensitivity analysis and is divided into five parts. The first part deals with the influence of pole width, the second studies the influence of pole height, the third studies the influence of stack length, the fourth studies the influence of yoke length, and the last studies the influence of air gap. Section V describes the experimental validation. The conclusions drawn from this research are presented in Section VI.

\section{AnAlytical ApProach}

This study was conducted on a high-force-density LSRM. This LSRM consists of three series-connected modules $(M=$ 3 ), each one formed by a four-phase double-sided magnetic structure with eight active poles per side $\left(N_{p}=8\right)$ and six passive poles per side $\left(N_{s}=6\right)$. One module of the LSRM is shown in Fig. 1 along with the geometrical parameters considered in this paper, which are $b_{p}, c_{p}, l_{p}, b_{s}, c_{s}, l_{s}, L_{W}$, $h_{y}$, and $g$. The number of phases $(m)$ and the stroke $(P S)$ can

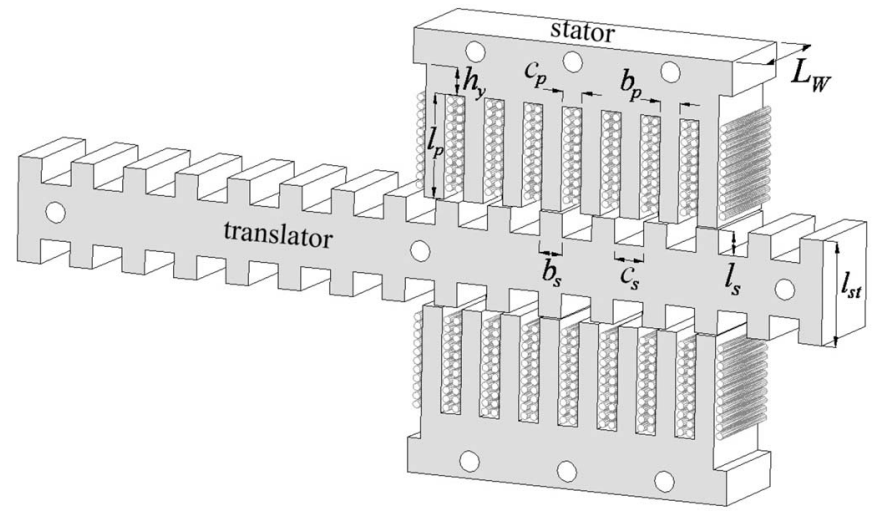

Fig. 1. Three-dimensional view of one module and main dimensions of the LSRM.

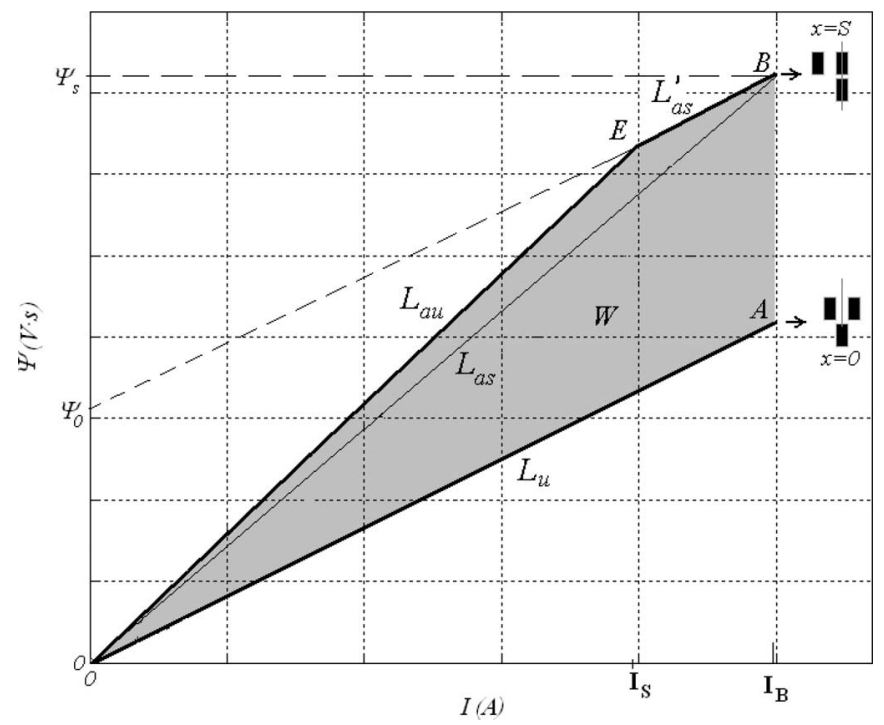

Fig. 2. Idealized nonlinear energy conversion cycle.

be taken as design parameters to determine $T_{p}, T_{s}, N_{p}$, and $N_{s}$ by means of the following:

$$
\left.\begin{array}{l}
T_{P}=\frac{1}{2} \cdot N_{S} \cdot P S=b_{p}+c_{p} \\
T_{S}=\frac{1}{2} \cdot N_{P} \cdot P S=b_{s}+c_{s}
\end{array}\right\}
$$

where

$$
\left.\begin{array}{l}
N_{P}=2 \cdot m \\
N_{S}=2 \cdot(m \pm 1)
\end{array}\right\}
$$

Average propulsion force can be calculated using an idealized nonlinear energy conversion loop in which the unaligned magnetization curve is assumed to be a straight line and the aligned magnetization curve is represented by two straight lines [18].

This simplified model accounts for the saturation effect and is shown in Fig. 2 by means of the lines OA (OA slope $\left.=L_{u}\right)$, $\mathrm{EB}\left(\mathrm{EB}\right.$ slope $\left.=L_{\mathrm{as}}^{\prime}\right)$, and $\mathrm{OE}\left(\mathrm{OE}\right.$ slope $\left.=L_{\mathrm{au}}\right)$. Assuming a flat-topped current waveform, the area OABEO is the energy conversion area $(W)$. Excluding iron and friction losses, the average propulsion force per phase $\left(F_{X, \text { avg }}\right)$ is then obtained by

$$
F_{X, \text { avg }}=\frac{W}{S}
$$


where $S$ is the distance between aligned and unaligned positions given by

$$
S=\left(b_{s}+c_{s}\right) / 2 \text {. }
$$

One of the limitations of the model is that the lines OA and EB are parallel and usually have saturated conditions $L_{\text {as }}^{\prime}<$ $L_{u}$. From Fig. 2, the following can be derived:

$$
\begin{aligned}
W & =\psi_{0} \cdot\left(I_{B}-\frac{1}{2} \cdot I_{S}\right) \\
\psi_{0} & =I_{B} \cdot\left(L_{\mathrm{as}}-L_{u}\right) \\
I_{S} \cdot\left(L_{\mathrm{au}}-L_{u}\right) & =\left(L_{\mathrm{as}}-L_{u}\right) \cdot I_{B} .
\end{aligned}
$$

By substituting (6) and (7) into (5) and operating

$$
W=I_{B}^{2} \cdot L_{\mathrm{as}} \cdot K_{L}
$$

where $K_{L}$ is a dimensionless coefficient defined by

$$
K_{L}=\left(1-\frac{L_{u}}{L_{\mathrm{as}}}\right) \cdot\left(1-\frac{1}{2} \cdot \frac{L_{\mathrm{as}}-L_{u}}{L_{\mathrm{au}}-L_{u}}\right)
$$

where (9) is studied in [18] and [19] for rotating SRMs.

At point $B$ (see Fig. 2), the poles are fully aligned, and therefore

$$
\psi_{S}=L_{\mathrm{as}} \cdot I_{B}=B_{p} \cdot N_{1} \cdot N_{\mathrm{pp}} \cdot b_{p} \cdot L_{W}
$$

The total ampere-turns per slot $\left(N_{1} \cdot I_{B}\right)$ can be expressed by means of the current density by

$$
N_{1} \cdot I_{B}=K_{s} \cdot \frac{c_{p} \cdot l_{p}}{2} \cdot J_{B}
$$

By substituting (10) and (11) in (8),

$$
W=\frac{1}{2} \cdot\left(K_{L} \cdot K_{s}\right) \cdot\left(c_{p} \cdot b_{p} \cdot l_{p} \cdot L_{W} \cdot N_{\mathrm{pp}}\right) \cdot\left(B_{p} \cdot J_{B}\right) .
$$

Considering a double-sided LSRM (see Fig. 1), the number of poles per phase $\left(N_{\mathrm{pp}}\right)$ is four $\left(N_{\mathrm{pp}}=2\right.$ in single-sided LSRM). The double-sided LSRM has the advantage that the translator does not support electromagnetic normal force; therefore, the mechanical losses due to friction are minimal, whereas, in the single-sided LSRM, the normal force between stator and translator can reach more than ten times the propulsion force.

By substituting (12) in (3) and considering (1), the average propulsion force per phase is

$$
\begin{aligned}
F_{X, \mathrm{avg}}=N_{\mathrm{pp}} \cdot\left(\frac{N_{s}}{N_{p}}\right) & \cdot\left(K_{L} \cdot K_{s}\right) \\
& \times\left(\frac{c_{p} \cdot b_{p} \cdot l_{p} \cdot L_{W}}{T_{P}}\right) \cdot\left(B_{p} \cdot J_{B}\right) .
\end{aligned}
$$

In order to obtain dimensionless variables, the geometrical variables shown in Fig. 1 are normalized by the stator-pole pitch

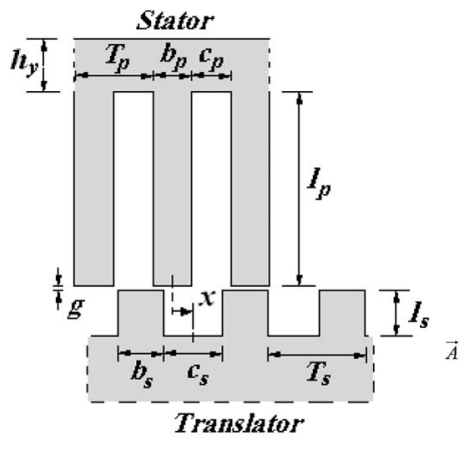

(a)

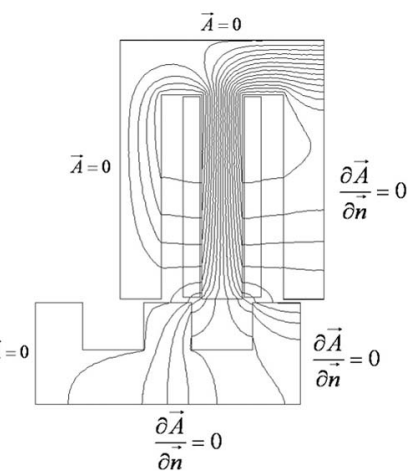

(b)
Fig. 3. Main dimensions and boundary conditions. (a) Main dimensions. (b) Boundary conditions.

$\left(T_{P}\right)$, obtaining

$$
\begin{aligned}
\alpha_{p} & =b_{p} T_{P} \\
\alpha_{s} & =b_{s} / T_{P} \\
\beta_{p} & =l_{p} / T_{P} \\
\beta_{s} & =l_{s} T_{P} \\
\gamma_{W} & =L_{W} / T_{P} \\
\delta_{y} & =h_{y} / T_{P} .
\end{aligned}
$$

Rewriting (13),

$$
\begin{aligned}
F_{X, \text { avg }}=N_{\mathrm{pp}} & \cdot\left(\frac{N_{s}}{N_{p}}\right) \cdot\left(K_{L} \cdot K_{s}\right) \\
& \times\left(\left(\alpha_{p}-\alpha_{p}^{2}\right) \cdot \beta_{p} \cdot \gamma_{W}\right) \cdot T_{P}^{3} \cdot\left(B_{p} \cdot J_{B}\right) .
\end{aligned}
$$

The average propulsion force (20) is parabolic for $\alpha_{p}$ and therefore has a maximum of $\alpha_{p}=0.5$ which can be found by fixing the remainder of the parameters and applying $\partial F_{X, \text { avg }} / \partial \alpha_{p}=0$. Equation (20) is a parametric expression that has the drawback that the coefficient $K_{L}$ must be chosen by experience; nevertheless, it can be useful as a first step in the design of LSRMs.

\section{Basis of Two-Dimensional Finite-ElEment SENSITIVITY ANALYSIS}

A 2-D finite-element solver was used to study the influence of different geometrical parameters on the inductance and force profile of the LSRM. Translator position is referred to as the $x$ variable, as shown in Fig. 3(a). In order to save computing time, the LSRM is broken down into the minimum repetition pattern that guarantees similar results to those obtained with the complete LSRM. To do this, the following two boundary conditions were established, as shown in Fig. 3(b). The first condition is the homogeneous condition (Dirichlet) and generally equals the magnetic vector potential $\boldsymbol{A}$ at zero. This condition is equivalent to an external material with null magnetic permeability; therefore, any flux line can cross this boundary. The second condition (Neumann) imposes a value on the normal derivative of $\boldsymbol{A}$ on the boundary. When this value is zero, it is equivalent 
to an external material with infinite magnetic permeability. Because this study was carried out with a minimum repetition pattern, this sensitivity analysis can also be applied to different kinds of LSRMs such as single-sided or modified high-forcedensity LSRMs [12].

End effects are not included in the 2-D FEA even though these effects increase inductances. Unaligned inductance, in particular, can be increased by up to $20 \%-30 \%$. The consequence of this is a decrease in the energy conversion area predicted by 2-D FEA and, therefore, a reduction in the performance calculations. End effects appear at the end of the laminations stack and are basically the consequence of extra flux linkages produced at the head or the end of the winding. This extra flux produces an axial fringing flux which, along with the steel imaging effect of the laminations, contributes to increasing these effects.

The most accurate manner of estimating end effects is probably by means of 3-D-FEA software packages, although they still require high computation time. In this paper, end effects are taken into account by means of a current- and positiondependent factor $K_{\mathrm{ee}}$ [22], an end-effect coefficient that corrects the results obtained by 2-D FEA in accordance with the following:

$$
\begin{aligned}
& \psi_{3 \mathrm{D}}=K_{\mathrm{ee}} \cdot \psi_{2 \mathrm{D}} \\
& L_{3 \mathrm{D}}=K_{\mathrm{ee}} \cdot L_{2 \mathrm{D}}
\end{aligned}
$$

where $\Psi_{2 \mathrm{D}}$ and $L_{2 \mathrm{D}}$ are the flux linkage and the inductance obtained by 2-D FEA and $\Psi_{3 \mathrm{D}}$ and $L_{3 \mathrm{D}}$ are the 3-D flux linkage and the inductance approaches that account for the end effects. End-effect coefficient $K_{\mathrm{ee}}$ is defined as [23]

$$
K_{\mathrm{ee}}=\left(1+L_{\mathrm{end}} / L_{2 \mathrm{D}}\right) \cdot K_{f} .
$$

$L_{\text {end }}$ is the end-winding inductance, and $K_{f}$ is the axial fringing factor. The axial fringing flux is due to the tendency of magnetic flux to bulge out in an axial direction. This effect depends on the translator position and is stronger when the poles are fully unaligned $(x=0)$ and weaker when they are completely aligned $(x=S)$. The axial fringing factor can therefore be calculated by [24]

$$
K_{f}(x)=1+l_{g}(x) / L_{W}
$$

where $l_{g}(x)$ is the length of the effective air gap. For the aligned position, $l_{g}(S)=g$, and for the unaligned position, $l_{g}(0)=g+l_{s}$. For intermediate positions $(0<x<S), l_{g}(x)$ can be modulated by a function $f_{m}(x)$, which results in

$$
l_{g}(x)=g+l_{s} \cdot f_{m}(x) .
$$

The modulation function that produces the most fitted results is

$$
f_{m}(x)=(1+\cos (\pi \cdot x / S)) / 2 .
$$

Therefore, the axial fringing factor results as

$$
K_{f}(x)=1+\left[g+0.5 \cdot l_{s} \cdot(1+\cos (\pi \cdot x / S))\right] / L_{W} .
$$

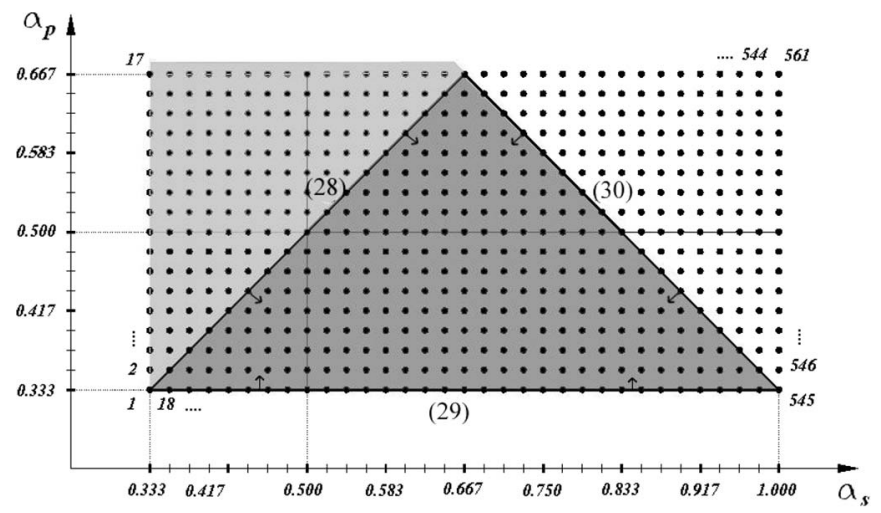

Fig. 4. Triangle for (dark) feasible configurations and (dots) scanning area.

\section{Sensitivity Analysis}

\section{A. Influence of Pole Widths $\left(b_{p}, b_{s}\right)$}

In the following analysis, the variables are $\alpha_{p}, \alpha_{s}$, and $x$. The other normalized geometrical parameters and the current density are held constant $\left(\beta_{p}=30 / T_{P}, \beta_{s}=7 / T_{P}, \gamma_{w}=\right.$ $120 / T_{P}, \delta_{y}=8 / T_{P}, J=15 \mathrm{~A} / \mathrm{mm}^{2}$, and $\left.g=0.5 \mathrm{~mm}\right)$. The interval of variation for $\alpha_{p}$ and $\alpha_{s}$ is limited by the Lawrenson criterion for feasible configurations [25] which defines a triangle as

$$
\begin{aligned}
\alpha_{p} & \leq \alpha_{s} \\
\alpha_{p} & \geq 2 / N_{s} \\
\alpha_{p}+\alpha_{s} & \leq T_{S} / T_{P} .
\end{aligned}
$$

These conditions are shown in Fig. 4 by the dark area. In order to obtain a wider scanning area, the dark triangle is framed in a dotted rectangle, as shown in Fig. 4. Each combination $\alpha_{p}$ and $\alpha_{s}$ is represented by a dot. The intervals are $\alpha_{p} \in\left[4 / T_{P}, 8 / T_{P}\right]$ and $\alpha_{s} \in\left[4 / T_{P}, 12 / T_{P}\right]$ with $\Delta \alpha_{p}=$ $\Delta \alpha s=1 /\left(4 \cdot T_{P}\right)$. The values of the translator position $x \in$ $[0, S]$ with $\delta x=S / 32$ are also implicit in each dot.

In the previous work [21], static force $F_{x}=f\left(\alpha_{p}, \alpha_{s}, x\right)$ and inductance $L=f\left(\alpha_{p}, \alpha_{s}, x\right)$ were analyzed in detail. Average force $\left(F_{X, \text { avg }}\right)$ and inductance ratio $\left(L_{a} / L_{u}\right)$ were introduced in order to evaluate the goodness of each static force and inductance profile

$$
\begin{aligned}
F_{x, \text { avg }}\left(\alpha_{p}, \alpha_{s}\right) & =\frac{1}{S} \int_{0}^{S} F_{x}\left(\alpha_{p}, \alpha_{s}, x\right) \cdot d x \\
L_{a} / L_{u}\left(\alpha_{p}, \alpha_{s}\right) & =L\left(\alpha_{p}, \alpha_{s}, S\right) / L\left(\alpha_{p}, \alpha_{s}, 0\right) .
\end{aligned}
$$

For brevity, only the average force results are shown in Fig. 5 . The inductance ratio did not reach a maximum within the feasible configurations. Fig. 5 shows that the average force is parabolic for $\alpha_{p}$ and that the maximum is near $\alpha_{p}=0.5$, as (20) predicts.

The average force results suggest that it could be optimized for the unit of copper mass $\left(M_{\mathrm{Cu}}\right)$ defined by

$$
M_{\mathrm{Cu}}=V_{\mathrm{Cu}} \cdot \gamma_{\mathrm{Cu}}
$$

where $\gamma_{\mathrm{Cu}}$ is the density of the copper and $V_{\mathrm{Cu}}$ is the total copper volume, which, for a semicircular end-winding 


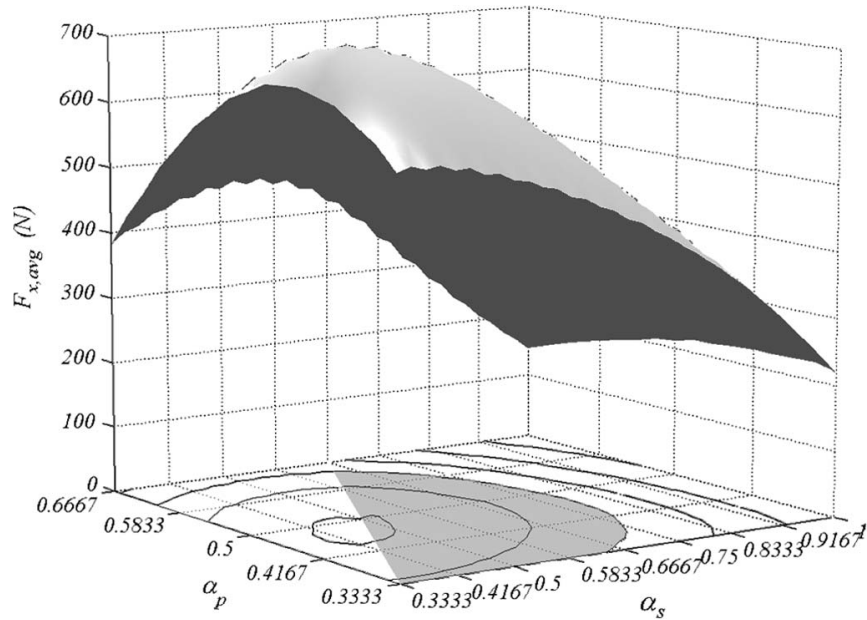

Fig. 5. Average force versus $\alpha_{s}$ and $\alpha_{p} . \quad F_{x \text {,avg }}=f\left(\begin{array}{ll}\alpha_{p} & \alpha_{s}\end{array}\right)$. $J=15 \mathrm{~A} / \mathrm{mm}^{2}$.

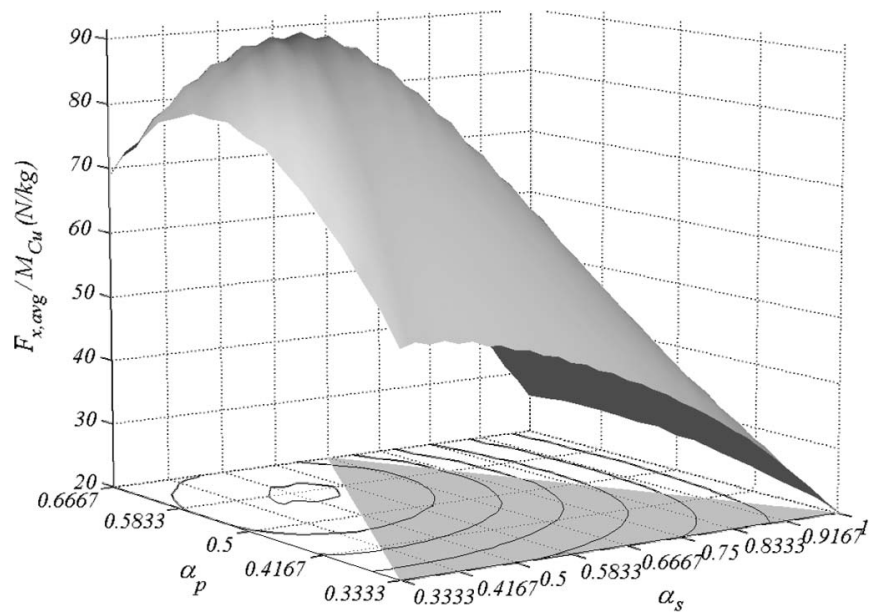

Fig. 6. Average force per unit of copper mass versus $\alpha_{s}$ and $\alpha_{p}$. $J=15 \mathrm{~A} / \mathrm{mm}_{2}$.

shape, is

$$
V_{\mathrm{Cu}}=\beta_{p} \cdot\left(1-\alpha_{p}\right) \cdot\left(\gamma_{W}+\frac{\pi}{4} \cdot\left(1+\alpha_{p}\right)\right) \cdot T_{p}^{3} \cdot N_{\mathrm{pp}} \cdot m \cdot M \cdot K_{s} .
$$

The average force per unit of copper mass is shown in Fig. 6, which shows that the maximum is placed higher than the maximum of average force for values of $\alpha_{p}$ (see Fig. 5).

The influence of current density $(J)$ is shown in Figs. 7 and 8, where the contour lines for several current densities are represented. The bright areas can be considered as optimal values of $\alpha_{p}$ and $\alpha_{s}$. As the figure shows, the optimal region goes up, increasing the value of $\alpha_{p}$ in proportion to the increase in current density.

\section{B. Influence of Pole Lengths $\left(l_{p}, l_{s}\right)$}

In this part of the analysis, the variables are $\beta_{p}, \beta_{s}$, and $x$. The other normalized geometrical parameters and the current density are held constant $\left(\alpha_{p}=5.75 / T_{P}, \alpha_{s}=\right.$ $6 / T_{P}, \gamma_{w}=120 / T_{P}, \delta_{y}=8 / T_{P}, J=15 \mathrm{~A} / \mathrm{mm}^{2}$, and $g=$ $0.5 \mathrm{~mm})$. The scanning intervals are $\beta_{p} \in\left[4 / T_{P}, 40 / T_{P}\right]$,
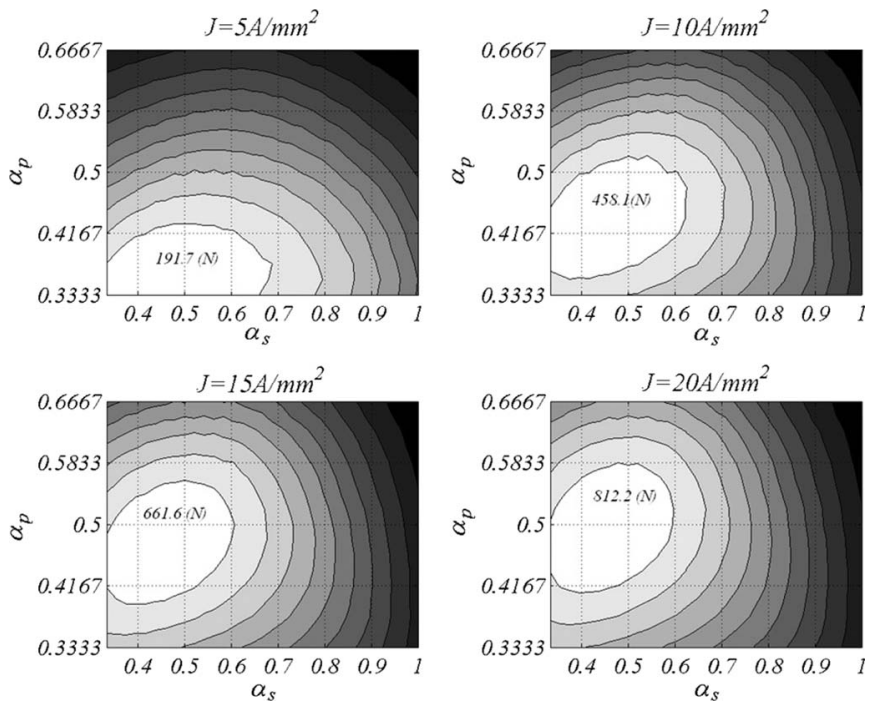

Fig. 7. Contour lines of average force for several current-density values.
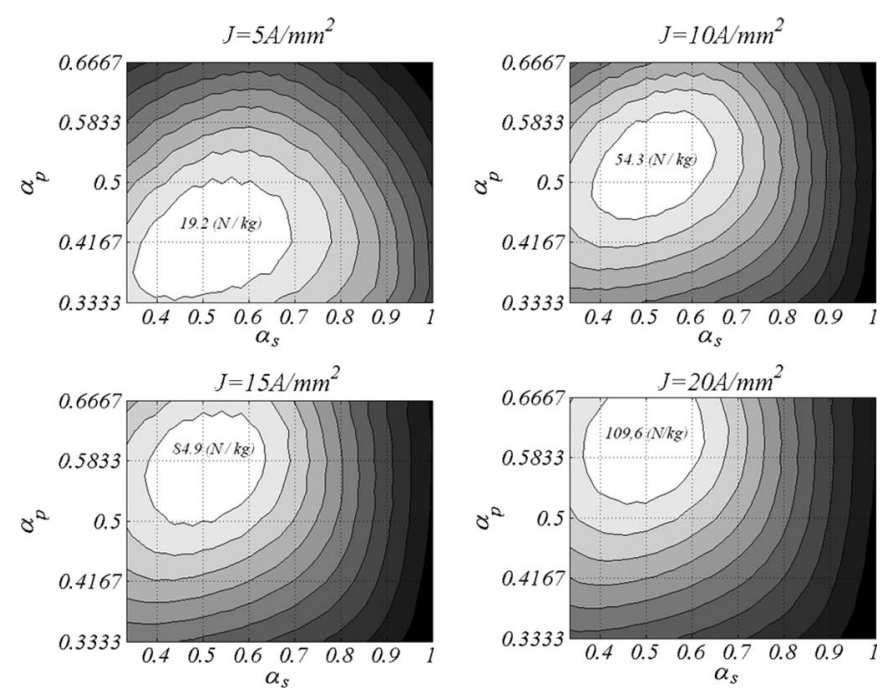

Fig. 8. Contour lines of average force per unit copper mass for several currentdensity values.

$\Delta \beta_{p}=1 / T_{P}, \beta_{s} \in\left[1 / T_{P}, 25 / T_{P}\right], \Delta \beta_{s}=1 / T_{P}$, and $x \in$ $[0, S], \Delta x=S / 16$.

The results are shown in Fig. 9. In order to plot the results $F_{x}\left(\beta_{p}, \beta_{s}, x\right)$, one of the variables has to be fixed. Fig. 9(a) shows the sensitivity of force profiles to $\beta_{s}$ fixing $\beta_{p}, F_{x}\left(3.333, \beta_{s}, x\right)$. Fig. 9(b) shows the sensitivity of force profiles to $\beta_{p}$ fixing $\beta_{s}, F_{x}\left(\beta_{p}, 0.5833, x\right)$. Stator-pole length has a much greater influence because it is related to the winding area; therefore, a longer stator pole means a higher peak and average force.

Fig. 9(c) shows the sensitivity of the average force $F_{x, \text { avg }}\left(\beta_{p}, \beta_{s}\right)$ for a fixed current density. As can be inferred from Fig. 9(c), the influence of the translator-pole length on force profiles is significant for values of $\beta_{s}$ lower than 0.5 $\left(6 / T_{P}\right)$. Above this value, there is no influence on average force. Fig. 9(d) shows the influence of the current density on the average force fixing $\beta_{s}$ higher than $0.5\left(\beta_{s}=1\right)$. As can be seen, values of $\beta_{p}$ higher than 2.5 do not produce any gain in the $F_{x \text {,avg }}$ for high-current-density values $\left(J \geq 15 \mathrm{~A} / \mathrm{mm}^{2}\right)$. 
(a)

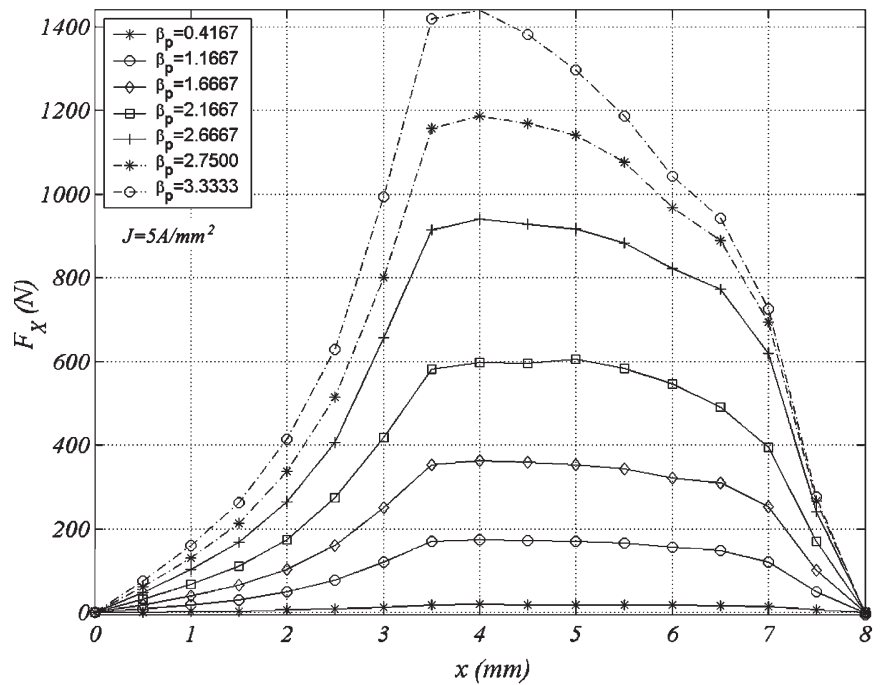

(c)

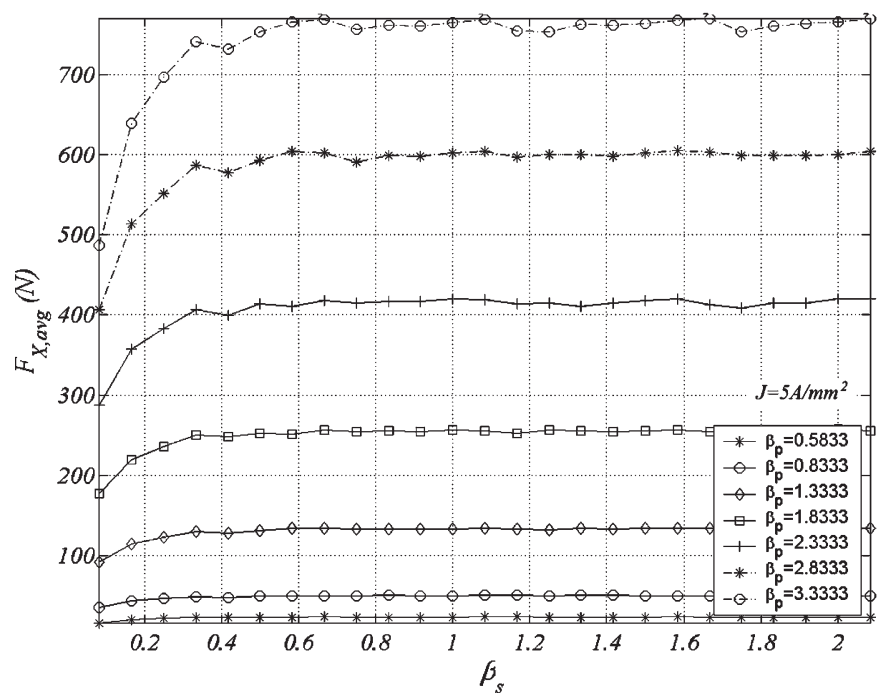

Fig. 9. Sensitivity of pole lengths.

\section{Influence of Stack Length $\left(L_{W}\right)$}

In this part of the analysis, the variables are $\gamma_{w}$ and $x$. The other geometrical parameters and the current density are held constant $\left(\alpha_{p}=5.75 / T_{P}, \alpha_{s}=6 / T_{P}, \delta_{y}=8 / T_{P}, J=\right.$ $15 \mathrm{~A} / \mathrm{mm}^{2}$, and $\left.g=0.5 \mathrm{~mm}\right)$. The scanning intervals are $\gamma_{w} \in$ $\left[10 / T_{P}, 120 / T_{P}\right], \Delta \gamma_{w}=5 / T_{P}$ and $x \in[0, S], \Delta x=S / 32$. Fig. 10 shows the results for $F_{x}\left(\gamma_{w}, x\right)$ and $F_{x \text {,avg }}\left(\gamma_{w}, J\right)$. Fig. 10(a) shows the sensitivity of $\gamma_{w}$ on force profiles. Fig. 10(b) shows the sensitivity of $\gamma_{w}$ on the average force for several current densities, which shows that average force increases linearly with stack length.

\section{Influence of Yoke Length $\left(h_{y}\right)$}

In this part of the analysis, the variables are $\delta_{y}$ and $x$. The other geometrical parameters are held constant $\left(\alpha_{p}=5.75 / T_{P}, \alpha_{s}=6 / T_{P}, \beta_{p}=30 / T_{P}, \beta_{s}=7 / T_{P}, \gamma_{w}=\right.$ $120 / T_{P}$, and $\left.g=0.5 \mathrm{~mm}\right)$.

The scanning intervals are $\delta_{y} \in\left[2 / T_{P}, 12 / T_{P}\right], \Delta \delta_{y}=$ $1 /\left(2 \cdot T_{P}\right)$ and $x \in[0, S], \Delta x=S / 32$. The results of the (b)

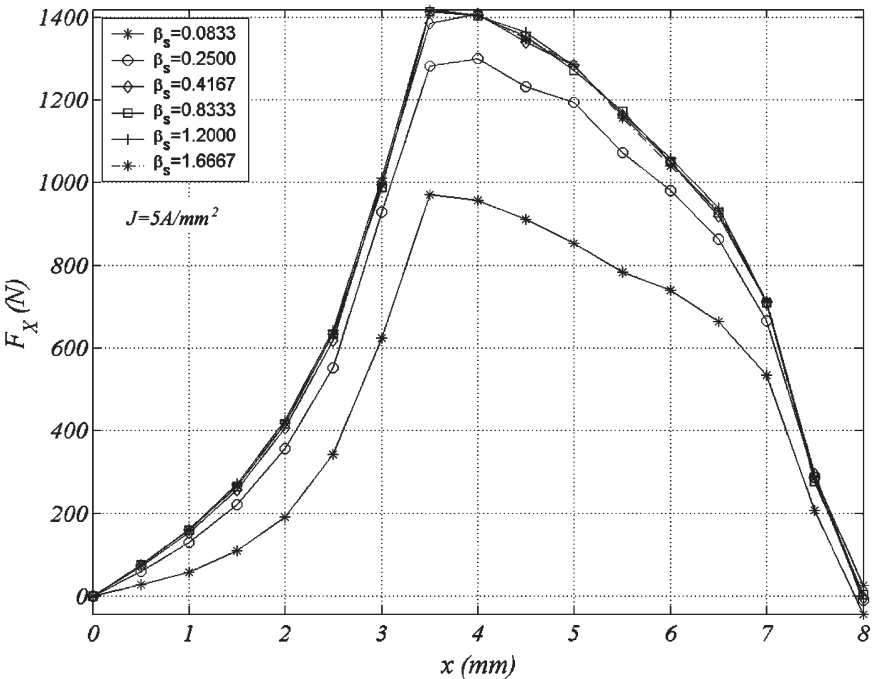

(d)

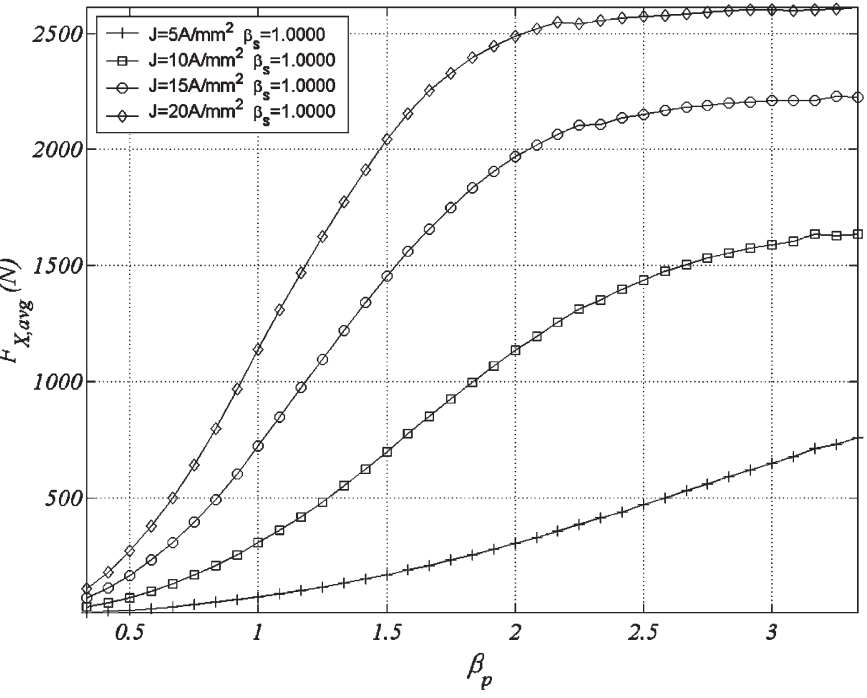

analysis are shown in Fig. 11. Fig. 11(a) shows the sensitivity of $\delta_{y}$ on force profiles $F_{x}\left(\delta_{y}, x\right)$ for a current density of $J=$ $15 \mathrm{~A} / \mathrm{mm}^{2}$. The influence of the yoke length on force for several current densities $F_{x, \text { avg }}\left(\delta_{y}, J\right)$ is significant for values of $\delta_{y}$ lower than $0.5417\left(6.5 / T_{P}\right)$ [Fig. 11(b)]. Above this value, there is no influence on the average force.

\section{E. Influence of Air-Gap Length $(g)$}

In LSRMs, the air gap does not condition any other dimension; therefore, the air gap does not need to be normalized. The variables in this part of the analysis are air-gap length $g$ and the position of the translator $x$. The other geometrical parameters and the current density are held constant: $\alpha_{p}=5.75 / T_{P}$, $\alpha_{s}=6 / T_{P}, \beta_{p}=30 / T_{P}, \beta_{s}=7 / T_{P}, \gamma_{w}=120 / T_{P}$, and $J=$ $15 \mathrm{~A} / \mathrm{mm}^{2}$. The scanning intervals are $g \in[0.3 \mathrm{~mm}, 1.4 \mathrm{~mm}]$, $\Delta g=0.1 \mathrm{~mm}$ and $x \in[0, S], \Delta x=S / 32$. Fig. 12(a) shows the sensitivity of force profiles $F_{x}(g, x)$. The sensitivity of airgap length $g$ on the average force $F_{x, \text { avg }}(g, x)$ can be seen in Fig. 12(b) and emphasizes the importance of air-gap length 
(a)

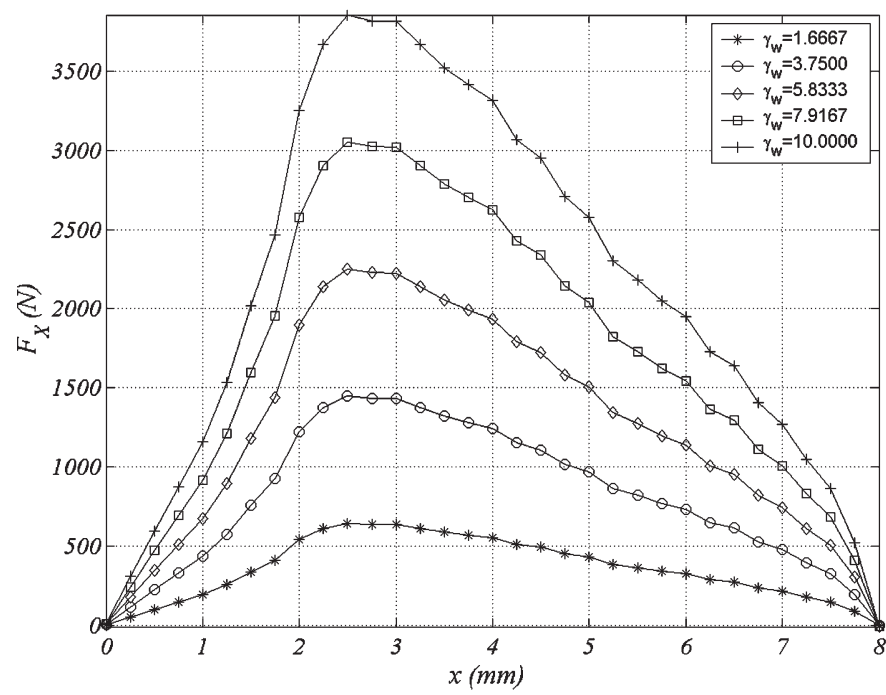

Fig. 10. Sensitivity of stack length.

(a)

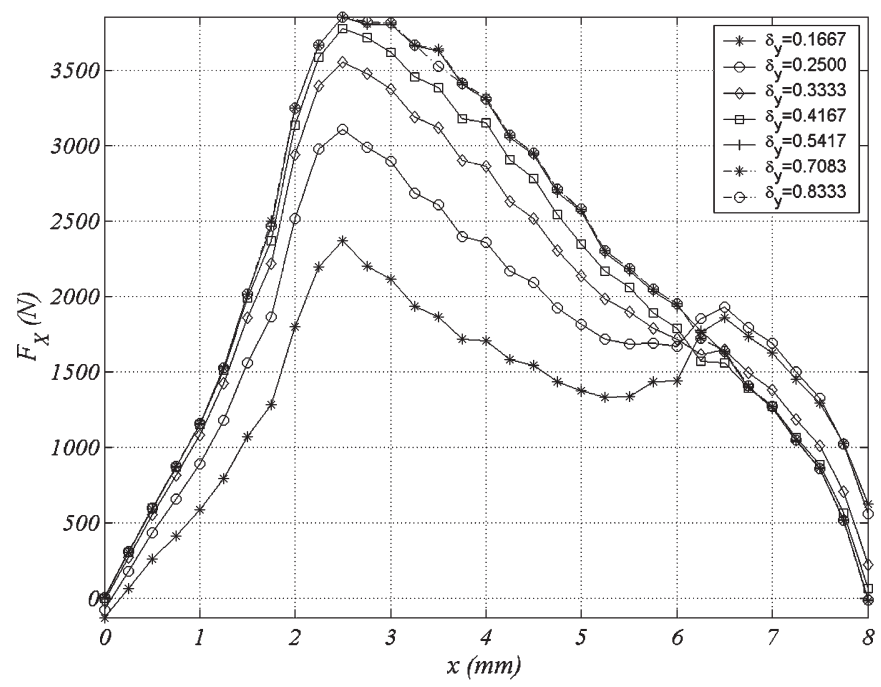

Fig. 11. Sensitivity of yoke length.

(a)

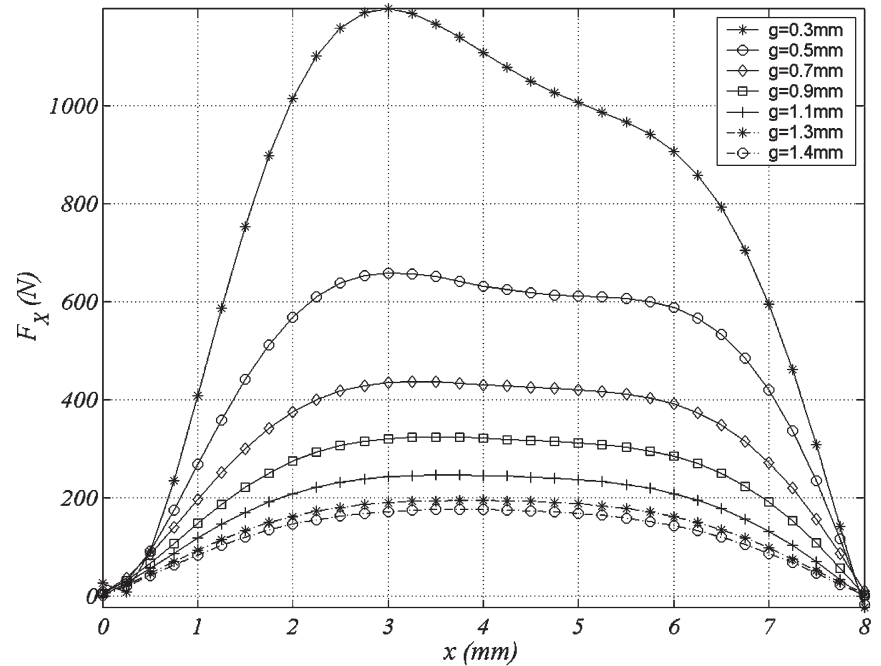

(b)

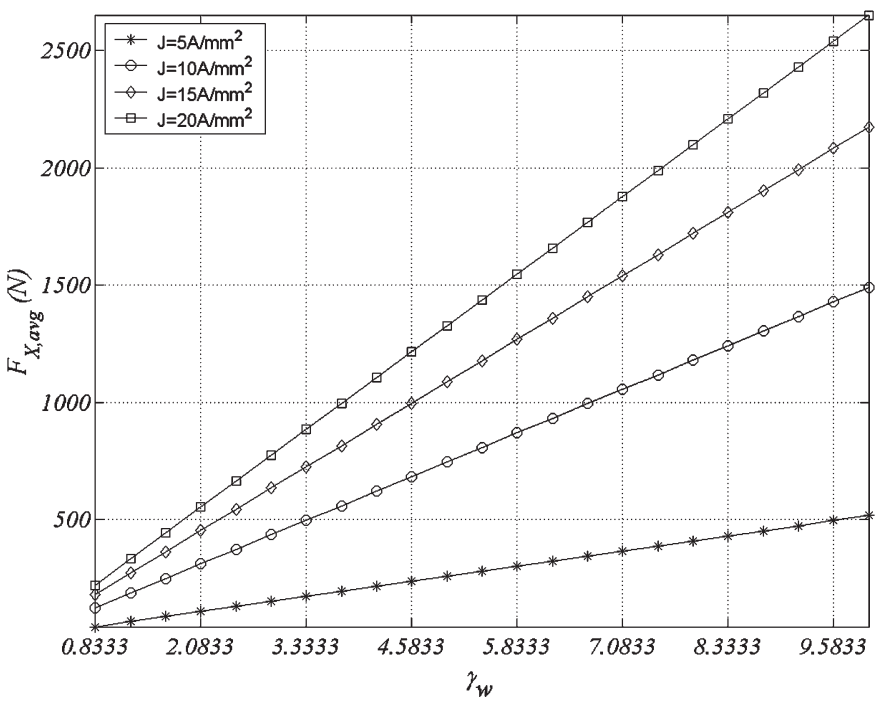

(b)

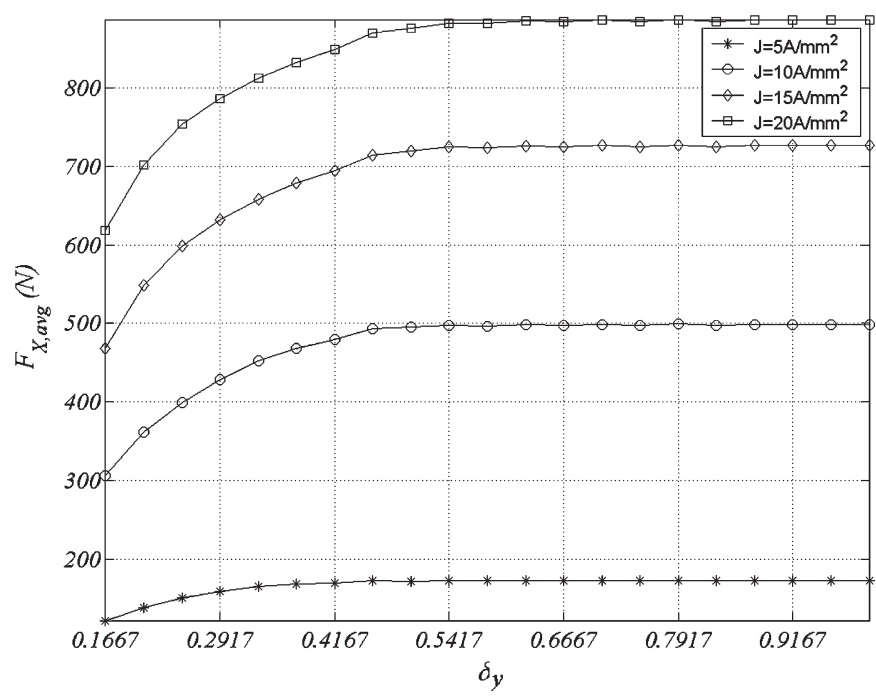

(b)

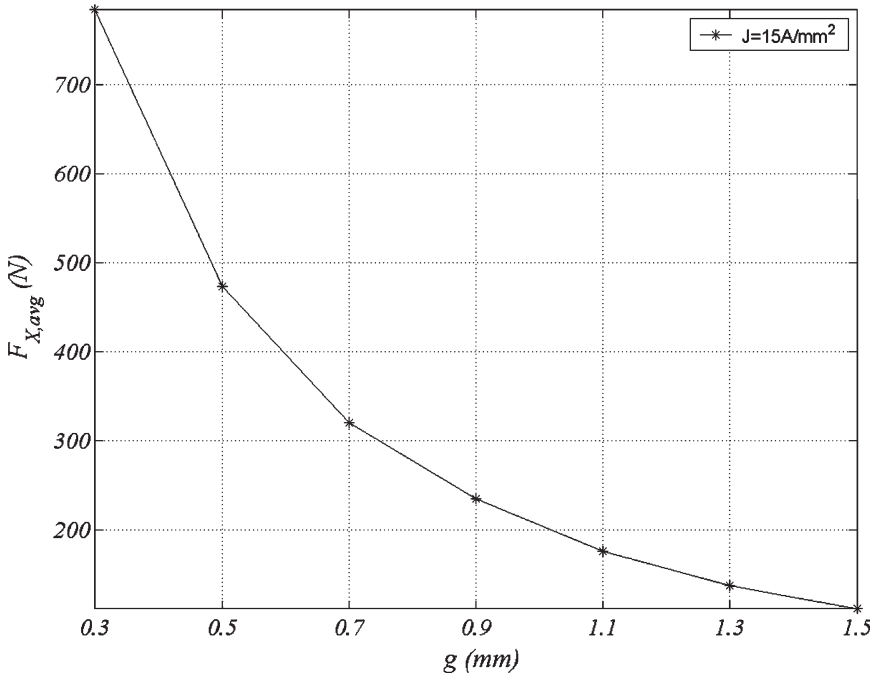

Fig. 12. Sensitivity of air-gap length. 
TABLE I

LSRM PROTOTYPE MAIN DimENSIONS

\begin{tabular}{|l|c|l|}
\hline Number of phases & $m$ & 4 \\
\hline Number of modules & $M$ & 1 \\
\hline Stator pole width & $b_{p}$ & $6(\mathrm{~mm})$ \\
\hline Stator slot width & $c_{p}$ & $6(\mathrm{~mm})$ \\
\hline Stator pole pitch & $T_{p}$ & $12(\mathrm{~mm})$ \\
\hline Number of active poles per side & $N_{p}$ & 8 \\
\hline Stator pole length & $l_{p}$ & $30(\mathrm{~mm})$ \\
\hline Translator pole width & $b_{S}$ & $7(\mathrm{~mm})$ \\
\hline Translator slot width & $c_{p}$ & $9(\mathrm{~mm})$ \\
\hline Translator pole pitch & $T_{p}$ & $16(\mathrm{~mm})$ \\
\hline Number of passive poles per side & $N_{S}$ & 6 \\
\hline Translator pole length & $l_{S}$ & $7(\mathrm{~mm})$ \\
\hline Yoke length & $h_{v}$ & $8(\mathrm{~mm})$ \\
\hline Stack length & $L_{W}$ & $30(\mathrm{~mm})$ \\
\hline Air gap length & $g$ & $0.5(\mathrm{~mm})$ \\
\hline Stroke & $P S$ & $4(\mathrm{~mm})$ \\
\hline Number of turns per pole & $N_{I}$ & 11 \\
\hline Wire diameter & $d_{c}$ & $2.1(\mathrm{~mm})$ \\
\hline Lamination steel & & $\begin{array}{l}\text { FeV 270-50HA } \\
(\mathrm{M} 19)\end{array}$ \\
\hline
\end{tabular}

TABLE II

LSRM PROTOTYPE NORMALIZED MAIN DIMENSIONS

\begin{tabular}{|l|c|l|}
\hline Normalized stator pole width & $\alpha_{p}$ & 0.5000 \\
\hline Normalized translator pole width & $\alpha_{s}$ & 0.5833 \\
\hline Normalized stator pole length & $\beta_{p}$ & 2.5000 \\
\hline Normalized translator pole length & $\beta_{s}$ & 0.5833 \\
\hline Normalized Yoke length & $\delta_{v}$ & 0.6667 \\
\hline Normalized Stack length & $\gamma_{W}$ & 2.5000 \\
\hline
\end{tabular}
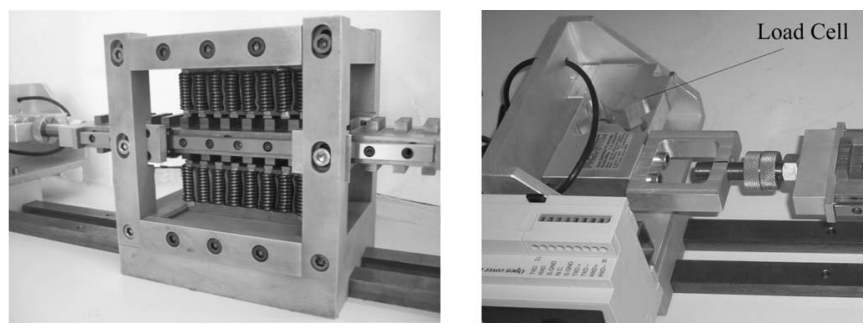

Fig. 13. View of LSRM prototype and load cell detail.

since a smaller air gap results in higher average force values, but there has to be a minimum air gap to allow for clearance and tolerances.

\section{EXPERIMENTAL VALIDATION}

An LSRM prototype was built and tested in order to provide a better illustration of the proposed 2-D finite-element sensitivity analysis and to evaluate the results.

The main dimensions of the LSRM prototype are shown in Table I. Table II shows the normalized main dimensions of the prototype optimized for the average force per unit copper mass and $J=10 \mathrm{~A} / \mathrm{mm}^{2}$.

Static propulsion force was measured directly by a load cell. A photograph of the LSRM prototype and a detailed view of the load cell are shown in Fig. 13. Fig. 14 shows a comparison of the force profiles obtained by 2-D FEA accounting for end effects and considering the minimum study pattern, those obtained by 2-D FEA accounting for end effects and considering the complete LSRM, and the measured values.

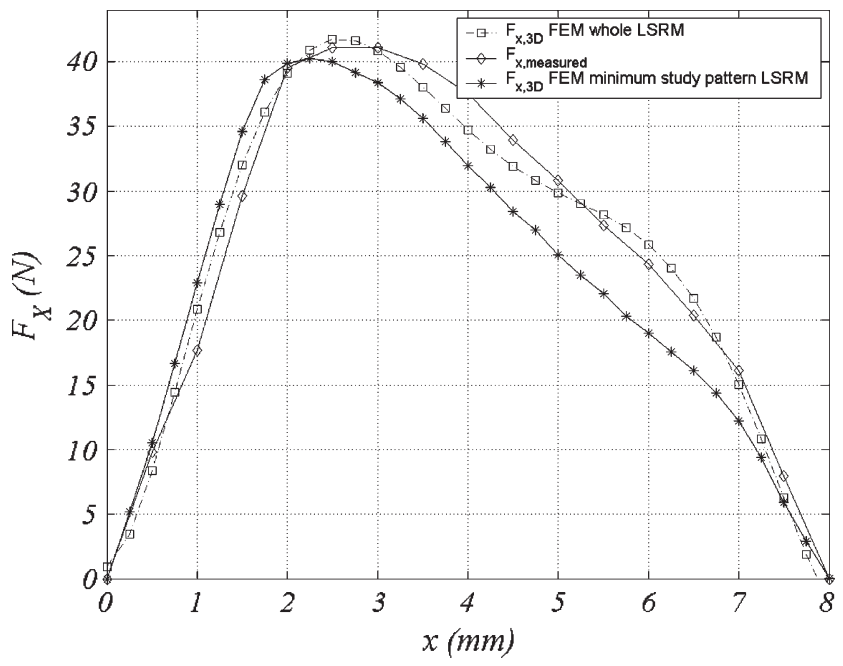

Fig. 14. Static propulsion force for $J=15 \mathrm{~A} / \mathrm{mm}^{2}$. Comparison results.

TABLE III

Average Force Results $\left(J=15 \mathrm{~A} / \mathrm{mm}^{2}\right)$

\begin{tabular}{|l|l|l|}
\hline Minimum study pattern & $F_{X, a v g}$ & $23.3(N)$ \\
\hline Complete LSRM & $F_{X, a v g}$ & $25.1(N)$ \\
\hline Analytical expression $(20)$ & $F_{x, \text { avg }}$ & $23.2(N)$ \\
\hline Measured values & $F_{X, a v g}$ & $24.5(N)$ \\
\hline
\end{tabular}

TABLE IV

INTERVALS FOR $K_{L}$

\begin{tabular}{|l|l|}
\hline$J=5 \mathrm{~A} / \mathrm{mm}^{2}$ & $0.268 \leq K_{L} \leq 0.304$ \\
\hline$J=10 \mathrm{~A} / \mathrm{mm}^{2}$ & $0.272 \leq K_{L} \leq 0.330$ \\
\hline$J=15 \mathrm{~A} / \mathrm{mm}^{2}$ & $0.215 \leq K_{L} \leq 0.292$ \\
\hline$J=20 \mathrm{~A} / \mathrm{mm}^{2}$ & $0.158 \leq K_{L} \leq 0.247$ \\
\hline
\end{tabular}

The average force results are listed in Table III. The $K_{L}$ coefficient defined in (9) depends on the geometrical parameters and the current density. Table IV shows the results obtained by the sensitivity FE analysis.

\section{CONCLUSiON}

This paper has investigated the influence of several geometrical parameters on the force profile of a double-sided LSRM. Experimental results confirm a good correlation between force and the proposed 2-D finite-element sensitivity study. If the maximum average force has to be an optimizing factor, the following rules concerning the geometrical parameters involved in the study could be useful.

1) Primary pole width: $\alpha_{p}=0.4167$ or $b_{p}=T_{P} / 2.4$ (see Fig. 7).

2) Secondary pole width: $\alpha_{s}=0.5$ or $b_{s}=T_{P} / 2$ (see Fig. 7).

3) The relation $b_{s}=1.2 b_{p}$ is a suitable design criterion for the pole widths.

4) Translator-pole length: $\beta_{s}=0.5$ or $l_{s}=T_{P} / 2$ [see Fig. 9(c)].

5) Stator-pole length: $l_{p}=2.5 \cdot T_{P}$ [see Fig. 9(d)].

6) Stack length $\left(L_{W}\right)$ is made to match the average force to the values expected from the design because the average force is proportional to $L_{W}$ [see Fig. 10(b)]. Nevertheless, an excessive stack increases the mass and iron losses. 
7) Yoke length: $\delta_{y}=0.5417$ or $h_{y}=T_{P} / 1.846 \quad$ [see Fig. 11(b)] to avoid saturation and loss of average thrust. Higher values do not have any influence and only increase the stator mass.

8) The air-gap length $(g)$ should be as small as possible to maximize the average force compatible with tolerances and manufacturing facilities [see Fig. 12(b)].

9) If the average force per unit of copper mass has to be considered, then the best value for the primary pole width is $\alpha_{p}=0.5$ or $b_{p}=T_{P} / 2$ (see Fig. 8 ).

\section{ACKNOWLEDGMENT}

The authors would like to thank Talleres Petit Industries for their collaboration.

\section{REFERENCES}

[1] T. J. E. Miller, Switched Reluctance Motor and Their Control. Hillsboro, OH: Magna Phys., 1993.

[2] G. Baoming, A. T. de Almeida, and F. Ferreira, "Design of transverse flux linear switched reluctance motor," IEEE Trans. Magn., vol. 45, no. 1, pp. 113-119, Jan. 2009.

[3] L. Byeong-Seok, B. Han-Kyung, V. Praveen, and R. Krishnan, "Design of a linear switched reluctance machine," IEEE Trans. Ind. Appl., vol. 36, no. 6, pp. 1571-1580, Nov./Dec. 2000.

[4] N. Chayopitak and D. G. Taylor, "Design of linear variable reluctance motor using computer-aided design assistant," in Proc. IEEE Int. Conf. Elect. Mach. Drives, May 2005, pp. 1569-1575.

[5] Z. Sun, N. C. Cheung, J. Pan, S. W. Zhao, and W.-C. Gan, "Design and simulation of a magnetic levitated switched reluctance linear actuator system for high precision application," in Proc. IEEE ISIE, Jun. 30-Jul. 2, 2008, pp. 624-629.

[6] U. S. Deshpande, J. J. Cathey, and E. Richter, "High-force density linear switched reluctance machine," IEEE Trans. Ind. Appl., vol. 31, no. 2, pp. 345-352, Mar./Apr. 1995.

[7] J. Pan, N. C. Cheung, and J. Yang, "High-precision position control of a novel planar switched reluctance motor," IEEE Trans. Ind. Electron., vol. 52, no. 6, pp. 1644-1652, Dec. 2005.

[8] S. W. Zhao, N. C. Cheung, W.-C. Gan, J. M. Yang, and J. F. Pan, "A self-tuning regulator for the high-precision position control of a linear switched reluctance motor," IEEE Trans. Ind. Electron., vol. 54, no. 5, pp. 2425-2434, Oct. 2007.

[9] L. Kolomeitsev, D. Kraynov, F. Pakhomin, F. Rednov, E. Kallenbach, V. Kireev, T. Schneider, and J. Böcker, "Linear switched reluctance motor as high efficiency propulsion system for railway vehicles," in Proc. SPEEDAM, 2008, pp. 155-160.

[10] H. S. Lim and R. Krishnan, "Ropeless elevator with linear switched reluctance motor drive actuation systems," IEEE Trans. Ind. Electron., vol. 54, no. 4, pp. 2209-2218, Aug. 2007.

[11] H. S. Lim, R. Krishnan, and N. S. Lobo, "Design and control of a linear propulsion system for an elevator using linear switched reluctance motor drives," IEEE Trans. Ind. Electron., vol. 55, no. 2, pp. 534-542, Feb. 2008.

[12] N. S. Lobo, H. S. Lim, and R. Krishnan, "Comparison of linear switched reluctance machines for vertical propulsion application: Analysis, design, and experimental correlation," IEEE Trans. Ind. Appl., vol. 44, no. 4, pp. 1134-1142, Jul./Aug. 2008.

[13] R. Arumugam, J. F. Lindsay, and R. Krishnan, "Sensitivity of pole arc/pole pitch ratio on switched reluctance motor performance," in Conf. Rec. IEEE IAS Anпи. Meeting, Pittsburgh, PA, Oct. 1988, vol. 1, pp. 50-54.
[14] J. Faiz and J. W. Finch, "Aspects of design optimization for switched reluctance motors," IEEE Trans. Energy Convers., vol. 8, no. 4, pp. 704713, Dec. 1993.

[15] S. S. Murthy, B. Singh, and V. K. Sharma, "Finite element analysis to achieve optimum geometry of switched reluctance motor," in Proc. IEEE TENCON, 1998, vol. 2, pp. 414-418.

[16] N. K. Sheth and K. R. Rajagopal, "Optimum pole arcs for a switched reluctance motor for higher torque with reduced ripple," IEEE Trans. Magn., vol. 39, no. 5, pp. 3214-3216, Sep. 2003.

[17] C. T. Liu and Y.-N. Chen, "On the feasible polygon classification of linear switched reluctance machines," IEEE Trans. Energy Convers., vol. 14, no. 4, pp. 1282-1287, Dec. 1999.

[18] T. J. E. Miller, "Converter volt-ampere requirements of the switched reluctance motor drive," IEEE Trans. Ind. Appl., vol. IA-21, no. 5, pp. 11361144, Sep./Oct. 1985.

[19] R. Krishnan, R. Arumugam, and J. F. Lindsay, "Design procedure for switched-reluctance motors," IEEE Trans. Ind. Appl., vol. 24, no. 3, pp. 456-461, May/Jun. 1988.

[20] I. Boldea and S. A. Nasar, Linear Electric Actuators and Generators. Cambridge, U.K.: Cambridge Univ. Press, 1997, pp. 173-175.

[21] J. G. Amoros, P. Andrada, L. Massagués, and P. Iñiguez, "Sensitivity analysis of several geometrical parameters on linear switched reluctance motor performance," in Proc. XVIII ICEM, Vilamoura, Portugal, Sep. 6-9, 2008, pp. 1-6.

[22] F. D'hulster, K. Stockman, and R. J. M. Belmans, "Modelling of switched reluctance machines: State of the art," Int. J. Model. Simul., vol. 24, no. 4, pp. 216-223, 2004.

[23] A. Matveev, V. Kuzmichev, and E. Lomonova, "A new comprehensive approach to estimation of end-effects in switched reluctance motors," in Proc. ICEM, Bruges, Belgium, Aug. 2002.

[24] T. J. E. Miller, "Optimal design of switched reluctance motors," IEEE Trans. Ind. Electron., vol. 49, no. 1, pp. 15-27, Feb. 2002.

[25] P. J. Lawrenson, J. M. Stephenson, P. T. Blenkinsop, J. Corda, and N. N. Fulton, "Variable-speed switched reluctance motors," Proc. Inst. Elect. Eng.-Elect. Power Appl., vol. 127, no. 4, pp. 253-265, Jul. 1980.

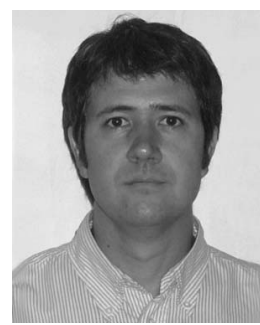

J. G. Amoros (M'09) received the M.Sc. degree in industrial engineering from the Universitat Politecnica de Catalunya (UPC), Barcelona, Spain, in 2004, where he is currently working toward the $\mathrm{Ph} . \mathrm{D}$. degree in electrical engineering.

Currently, he is also an Associate Professor of electrical machines at the Universitat Rovira i Virgili, Tarragona, Spain. His research interests are in the area of design and modeling of electrical machines and drives.

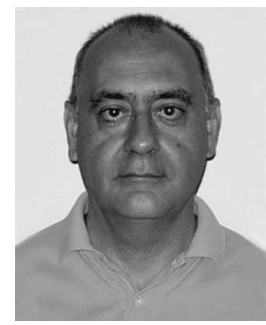

P. Andrada (M'91) received the M.Sc. and Ph.D. degrees in industrial engineering from the Universitat Politecnica de Catalunya (UPC), Barcelona, Spain, in 1980 and 1990, respectively.

In 1980, he joined the Department of Electrical Engineering, UPC, where he is currently an Assistant Professor in the Engineering School of Vilanova i la Geltrú (EPSEVG). His research interests are in the area of design and modeling of electrical machines and drives. 